\title{
openheart Evidence from randomised controlled trials does not support current dietary fat guidelines: a systematic review and meta-analysis
}

\author{
Zoë Harcombe, ${ }^{1}$ Julien S Baker, ${ }^{1}$ James J DiNicolantonio, ${ }^{2}$ Fergal Grace, ${ }^{1}$ \\ Bruce Davies ${ }^{3}$
}

To cite: Harcombe Z, Baker JS, DiNicolantonio JJ, et al. Evidence from randomised controlled trials does not support current dietary fat guidelines: a systematic review and metaanalysis. Open Heart 2016;3 e000409. doi:10.1136/ openhrt-2016-000409

Received 15 January 2016 Revised 20 April 2016 Accepted 1 July 2016

\section{${ }^{1}$ Institute of Clinical Exercise and Health Science, University of the West of Scotland, Lanarkshire, UK 2Saint Luke's Mid America Heart Institute, Kansas City, Missouri, USA \\ ${ }^{3}$ University of South Wales, Pontypridd, UK}

Correspondence to Zoë Harcombe;

Zoe.Harcombe@uws.ac.uk

\section{ABSTRACT}

Objectives: National dietary guidelines were introduced in 1977 and 1983, by the USA and UK governments, respectively, with the ambition of reducing coronary heart disease (CHD) mortality by reducing dietary fat intake. A recent systematic review and meta-analysis by the present authors, examining the randomised controlled trial (RCT) evidence available to the dietary committees during those time periods, found no support for the recommendations to restrict dietary fat. The present investigation extends our work by re-examining the totality of RCT evidence relating to the current dietary fat guidelines.

Methods: A systematic review and meta-analysis of RCTs currently available, which examined the relationship between dietary fat, serum cholesterol and the development of $\mathrm{CHD}$, was undertaken.

Results: The systematic review included 62421 participants in 10 dietary trials: 7 secondary prevention studies, 1 primary prevention and 2 combined. The death rates for all-cause mortality were $6.45 \%$ and $6.06 \%$ in the intervention and control groups, respectively. The risk ratio (RR) from meta-analysis was $0.991(95 \% \mathrm{Cl} 0.935$ to 1.051). The death rates for CHD mortality were $2.16 \%$ and $1.80 \%$ in the intervention and control groups, respectively. The RR was $0.976(95 \% \mathrm{Cl} 0.878$ to 1.084$)$. Mean serum cholesterol levels decreased in all intervention groups and all but one control group. The reductions in mean serum cholesterol levels were significantly greater in the intervention groups; this did not result in significant differences in CHD or all-cause mortality. Conclusions: The current available evidence found no significant difference in all-cause mortality or CHD mortality, resulting from the dietary fat interventions. RCT evidence currently available does not support the current dietary fat guidelines. The evidence per se lacks generalisability for population-wide guidelines.

\section{INTRODUCTION}

US public health dietary advice was announced by the Select Committee on Nutrition and Human Needs in $1977^{1}$ and was followed by UK public health dietary

\section{KEY QUESTIONS}

What is already known about this subject?

- Dietary recommendations were introduced in the USA (1977) and in the UK (1983) to (i) reduce overall fat consumption to $30 \%$ of total energy intake and (ii) reduce saturated fat consumption to $10 \%$ of total energy intake. We recently reported, in a previous meta-analysis, that the available randomised controlled trial (RCT) evidence did not support the introduction of these dietary fat guidelines. Further, we reported that the RCTs were undertaken on 2467 men from exclusively or largely secondary prevention studies.

What does this study add?

- RCT evidence currently available does not support the current recommendations to restrict dietary fat. The lack of generalisability of current evidence prevails. This study finds that only one primary prevention RCT, including men and women, is available to inform public health advisors and that this was without statistical significance.

How might this impact on clinical practice?

- Public health advice on dietary fat has prevailed since 1977/1983 in the absence of supporting evidence from RCTs. The US 2015 draft dietary guidelines exclude recommendations for total fat for the first time, but maintain the advice to restrict saturated fat. The current evidence does not support this recommendation. The UK advice has not changed since 1983. Clinicians would be justified in taking a more cautionary approach to their advising of patients on these dietary fat recommendations.

advice issued by the National Advisory Committee on Nutritional Education in $1983 .^{2}$ Dietary recommendations in both cases focused on reducing dietary fat intake, specifically to (i) reduce overall fat consumption to $30 \%$ of total energy intake and (ii) 
reduce saturated fat (SFA) consumption to $10 \%$ of total energy intake.

The recommendations were intended to address mortality from coronary heart disease (CHD). We recently published a systematic review and meta-analysis, ${ }^{3}$ which reported that evidence from randomised controlled trials (RCTs), available to the dietary guideline committees, did not support the introduced dietary fat recommendations. This systematic review and meta-analysis extends this work by re-examining the totality of RCT evidence, currently available, relating to the present dietary fat guidelines.

While no previous study had reviewed the evidence available to the 1977 and 1983 committees, a number of meta-analyses have reviewed RCT and/or epidemiological evidence available at their respective times of publication. ${ }^{4-11}$ None has found any significant result for dietary fat intervention and mortality: all-cause, cardiovascular disease (CVD) or CHD mortality.

A meta-analysis by Skeaff and Miller in 2009 included 28 US and European cohorts (6600 CHD deaths among 280000 participants) and found no clear relationship between total or SFA intake and CHD events or deaths. ${ }^{4}$

In 2010, Siri-Tarino et a $\tilde{e}$ undertook a meta-analysis of 21 prospective cohort studies involving 347747 participants, evaluating the association of SFA with CVD. They reported that there is no significant evidence for concluding that dietary SFA is associated with an increased risk of CHD or CVD.

Hooper et at ${ }^{7}$ examined RCT evidence in 2011 and 2015 and found no significant difference for total mortality or cardiovascular mortality resulting from modified dietary fat intake, reduced dietary fat intake or combined modified and reduced dietary fat intake.

Chowdhury et $a l \mathrm{~s}^{8}$ meta-analysis of RCTs and prospective cohort studies found no association of dietary SFA intake, nor of circulating SFAs, with CHD.

Schwingshackl and Hoffmann examined RCTs that reduced or modified dietary fat with regard to all-cause mortality, CVD mortality and CVD events, in participants with established CHD. They concluded that there was no evidence for benefit of reduced/modified fat diets in the secondary prevention of CHD. ${ }^{9}$

Mozaffarian et $a l^{10}$ reported evidence that consuming polyunsaturated fats in place of SFAs reduced CHD events, not mortality, in RCTs.

A number of these reviews have been challenged. Stamler posed questions following the Siri-Tarino et al publication. ${ }^{12}$ Chowdhury et $a l \mathrm{~s}^{8}$ meta-analysis received a number of letters of response, which led to the original article being amended. Mozaffarian $e t a l$ s review was criticised ${ }^{13}$ for excluding two unfavourable trials ${ }^{14} 15$ and for including the non-randomised, cross-over trial excluded by other reviews. ${ }^{16} 17$

The most recent meta-analysis by Hooper et $a l^{7}$ suggested that reduction of SFA intake may result in a small but potentially important reduction in cardiovascular risk, not mortality.
There were two important findings of Harcombe et $a l^{3}{ }^{3}$ first, the evidence available to the dietary committees did not support the introduced guidelines; second, the evidence available had serious limitations and was inappropriate to use for population-wide recommendations. The six studies available in $1983^{14}{ }^{15}{ }^{18-21}$ had reviewed 2467 men and no women. Five of the six studies were secondary prevention; one included primary and secondary prevention subjects. ${ }^{21}$

Based on these secondary findings, selection criteria for meta-analysis to inform population-wide recommendations should be restricted to RCTs, of sufficient size and duration, with primary prevention subjects, man and woman. There is only one study meeting these criteria, ${ }^{22}$ the Minnesota Coronary Survey, and the results of this were not significant.

As a meta-analysis cannot be undertaken on the one primary prevention, both-sex, study available, this follow-up study retains the selection criteria and thus limitations of Harcombe et $a \hat{l}$ to re-examine dietary guidelines, for total and SFA, to assess their evidence base against the RCT evidence currently available.

\section{METHODS}

A systematic review and meta-analysis was conducted in accordance with the Preferred Reporting Items for Systematic Reviews and Meta-Analyses (PRISMA) guidelines. $^{23}$

\section{Search strategy}

A search was undertaken to identify RCTs that examined the relationship between modified or reduced dietary fat intake, serum cholesterol and mortality from CHD and all-causes. Exclusion criteria were as follows: study being observational; non-randomised and/or multifactorial in design. Inclusion criteria were as follows: randomised dietary intervention study; study hypothesis relating to a reduction or modification of dietary fat; participants were human adults; study was a minimum of 1 year in duration; primary study outcome was all-cause and CHD mortality; and data on all-cause mortality, CHD mortality and cholesterol measurements were available.

Searches were performed of the literature using MEDLINE, Embase and the Cochrane Library. AMED and SIGLE (grey literature sources) were not relied upon, as their periods covered were not compatible: 1985 and 1992, respectively ${ }^{24}$ (figure 1).

\section{Selection of studies}

Of 486 identified articles, 346 were rejected on review of the title and abstract. Of these, 119 were rejected for being review, discussion or historical articles. In total, 88 were commentaries, editorials or letters. A total of 48 were rejected for having an intervention relating to a particular food or supplement, rather than dietary fat. There were 30 studies where animals or children/ 


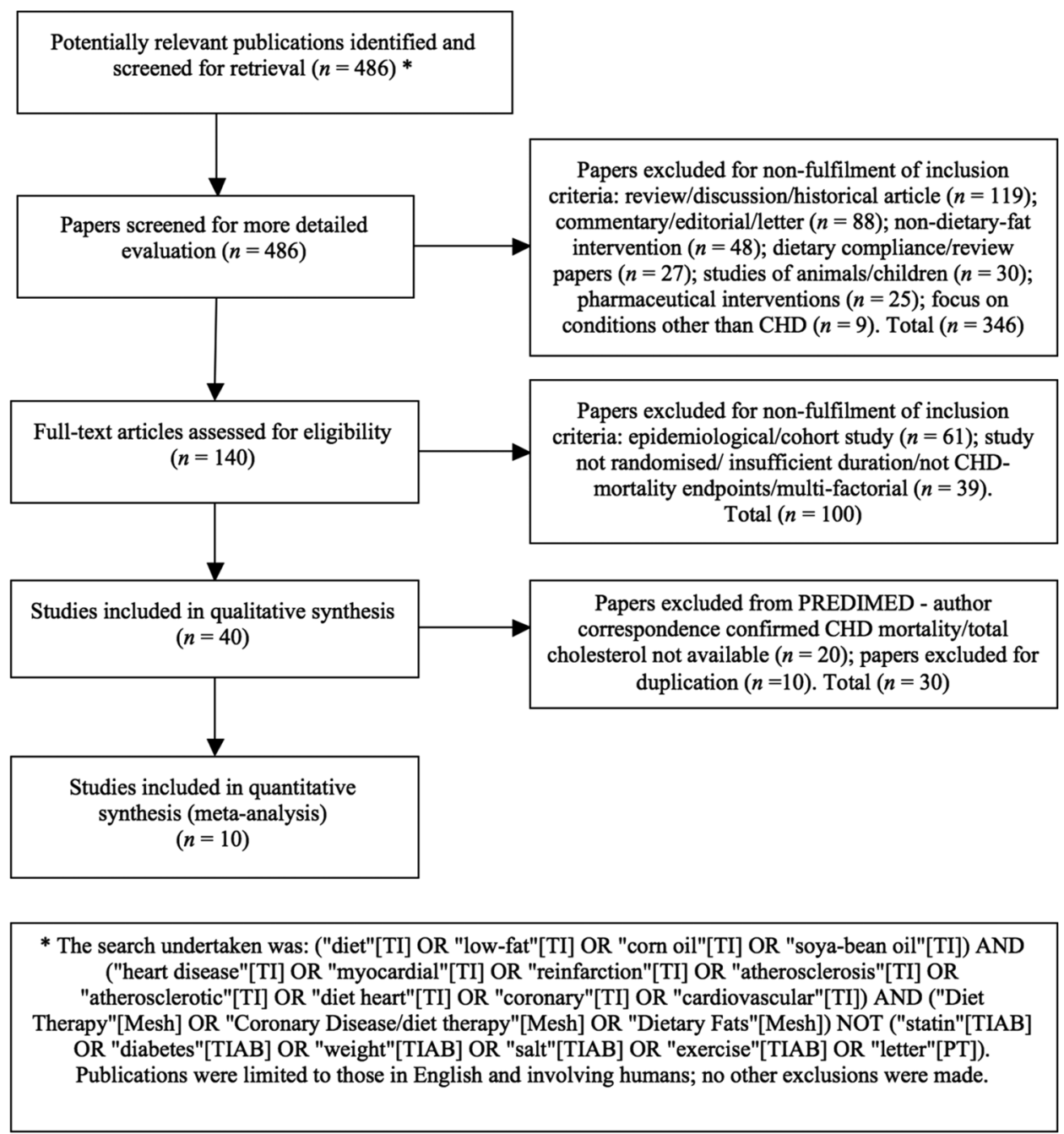

Figure 1 Summary of systematic review profile. CHD, coronary heart disease; PREDIMED, PREvención con Dleta MEDiterránea study.

adolescents were the primary focus. A further 27 papers considered the design and challenges of dietary interventions, for example examining the difficulties of achieving compliance. In total, 25 were rejected for being surgical and/or pharmacological interventions. Nine related to conditions other than CHD, such as cancer and stress. Finally, 140 papers remained, of which 61 were rejected on closer inspection of the paper for being epidemiological/cohort studies and 39 were rejected for not meeting the inclusion criteria.

The remaining 40 papers covered 11 trials, once duplication was resolved. In total, 10 RCTs met the inclusion criteria: Rose Corn Oil Trial; ${ }^{14}$ Research Committee Low-fat Diet; ${ }^{19}$ Medical Research Council (MRC) Soya-bean Oil Trial ${ }^{18}$ LA Veterans Study; ${ }^{21}$ the Oslo Diet-Heart Study; ${ }^{20}{ }^{26}$ the Sydney Diet Heart Study; ${ }^{15}$ the dietary fat intervention from the Diet and Reinfarction Trial (DART) $;{ }^{27}$ the Minnesota Coronary Survey; ${ }^{22}$ the St Thomas' Atherosclerosis Regression Study (STARS) ${ }^{28}$ and the Women's Health Initiative (WHI) ${ }^{29}$ Following correspondence, the PREvención con DIeta MEDiterránea (PREDIMED) study $^{30}$ was rejected for non-availability of CHD mortality and total cholesterol data.

To ascertain the validity of eligible randomised trials, a pair of reviewers (ZH and $\mathrm{BD}$ ) worked independently to determine which studies met the inclusion criteria. The same 10 were agreed on. Risk of bias was further assessed using the Cochrane Collaboration assessment tool $^{31}$ for selection bias (random sequence generation, allocation concealment); performance/detection bias (blinding of participants and personnel, blinding of outcome assessment); attrition bias (incomplete data outcome); and reporting bias (selective reporting) (figure 2). Additionally, the meta-analyses for all-cause mortality (figure 3) and CHD deaths (figure 4) were tested for sensitivity analysis of the exclusion of any one study.

\section{Data extraction}

Table 1 details data extraction including study name, duration, year of publication and confirmation of study 
design; participant characteristics; details of intervention and comparison diet; and outcomes relating to all-cause mortality, CHD-related deaths and changes in mean serum cholesterol levels. Where a study contained more than one intervention, both were included, ${ }^{14} 22$ which resulted in 12 interventions for review.

\section{Statistical analysis}

The overall pooled effect was calculated using random-effects meta-analysis. Heterogeneity and bias

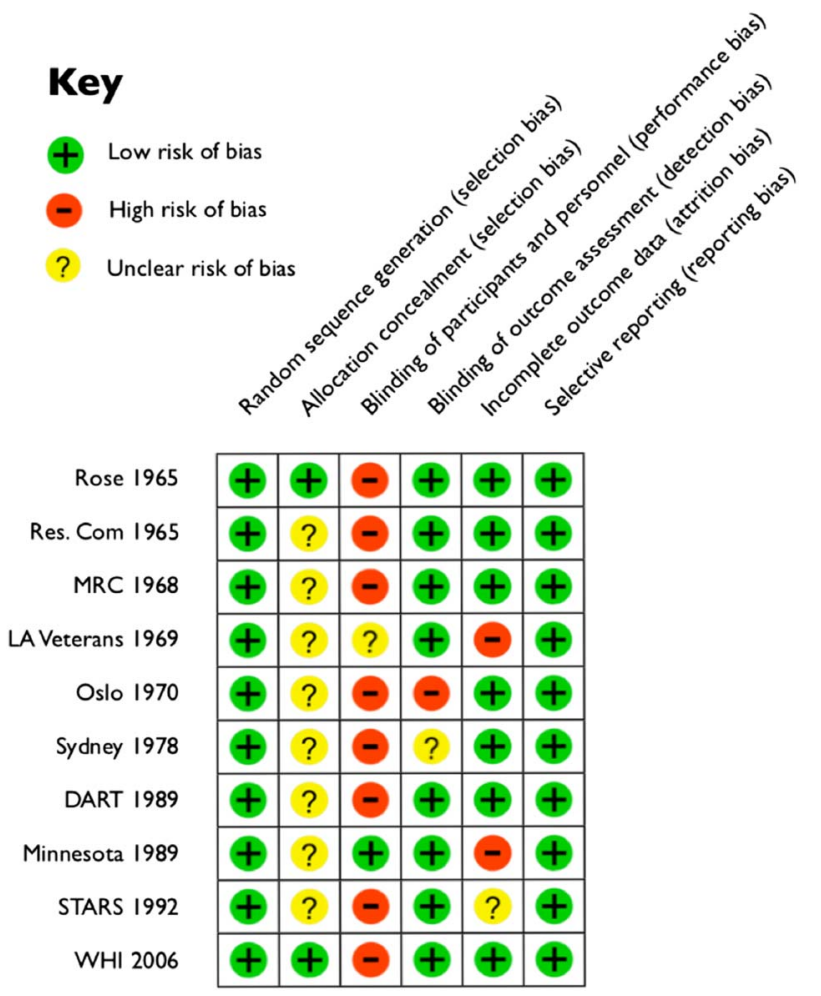

Figure 2 Methodological quality summary: review authors' judgements about each methodological quality item for each included study. DART, Diet and Reinfarction Trial; MRC, Medical Research Council; STARS, St Thomas' Atherosclerosis Regression Study; WHI, Women's Health Initiative.

Figure 3 Estimates of total mortality $(95 \% \mathrm{Cls})$ from meta-analysis for all deaths. DART, Diet and Reinfarction Trial; MRC, Medical Research Council; STARS, St Thomas' Atherosclerosis Regression Study; WHI, Women's Health Initiative. were quantified using the $\mathrm{I}^{2}$ and $\mathrm{T}^{2}$ calculations, $\mathrm{I}^{2}=100 \% \times(\mathrm{Q}-\mathrm{df}) / \mathrm{Q}$, where $\mathrm{Q}$ is Cochran's heterogeneity statistic and $\mathrm{df}$ is the degrees of freedom. Funnel plot methodology and Egger's regression intercept ${ }^{32} 33$ were calculated. Analyses were performed using Comprehensive Meta-Analysis. ${ }^{34}$

\section{RESULTS}

\section{Participants and study design}

The 10 identified RCTs included a total of 3888 deaths from all-causes and 1218 deaths from CHD among 62421 participants (table 1). The most recent trial, the WHI, dominated the data pool with $78 \%$ of the participants, ${ }^{29}$ but the results remained non-significant with the exclusion of this study. Excluding this study leaves 13586 participants and results in a risk ratio (RR) for all-cause mortality from meta-analysis of 1.005 (95\% CI 0.922 to 1.097) and a RR for CHD mortality from meta-analysis of 0.962 (95\% CI 0.850 to 1.089 ) (both random-effects methodology).

The WHI trial was a primary and secondary prevention trial for women only. The Minnesota Coronary Survey was a primary prevention study, with data for men and women reported separately. ${ }^{22}$ The LA Veterans Study $^{21}$ comprised one-fifth secondary and four-fifths primary prevention subjects. The remaining studies were secondary prevention studies with exclusively male participants.

The mean duration of the 10 trials was $4.7 \pm 3.3$ years. The weighted mean duration (person years by participants) was $6.8 \pm 2$ years.

All trials were parallel and randomised, avoiding selection bias (figure 2). ${ }^{31}$ Two studies reported allocation concealment; ${ }^{14}{ }^{29}$ the remaining eight were unclear for this aspect of selection bias. Eight were blinded for outcome assessment ${ }^{14} \begin{array}{lllllll}18 & 19 & 22 & 27-29 & \text { and }\end{array}$ thus at low risk of detection bias. Two were open, with no, or unclear, blinding on either side, ${ }^{15}{ }^{20}$ at high risk of performance and detection bias. The LA Veterans Study ${ }^{21}$ was reported as double blinded, but the dietary changes were so substantial that this was
Dietary Intervention \& All Deaths

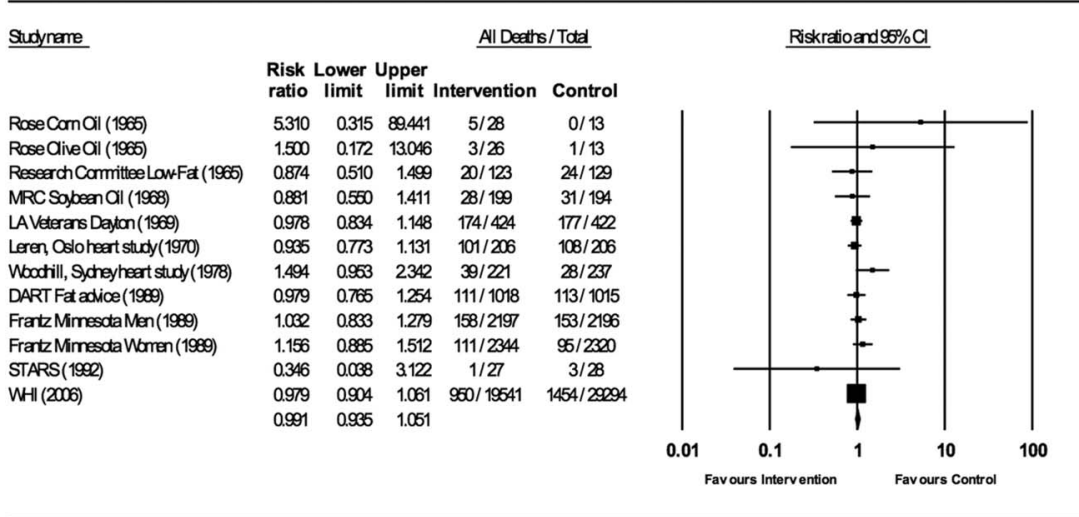


Figure 4 Estimates of total mortality (95\% Cls) from meta-analysis for CHD deaths.

DART, Diet and Reinfarction Trial;

MRC, Medical Research Council; STARS, St Thomas'

Atherosclerosis Regression Study; WHI, Women's Health Initiative.
Dietary Intervention \& CHD Deaths

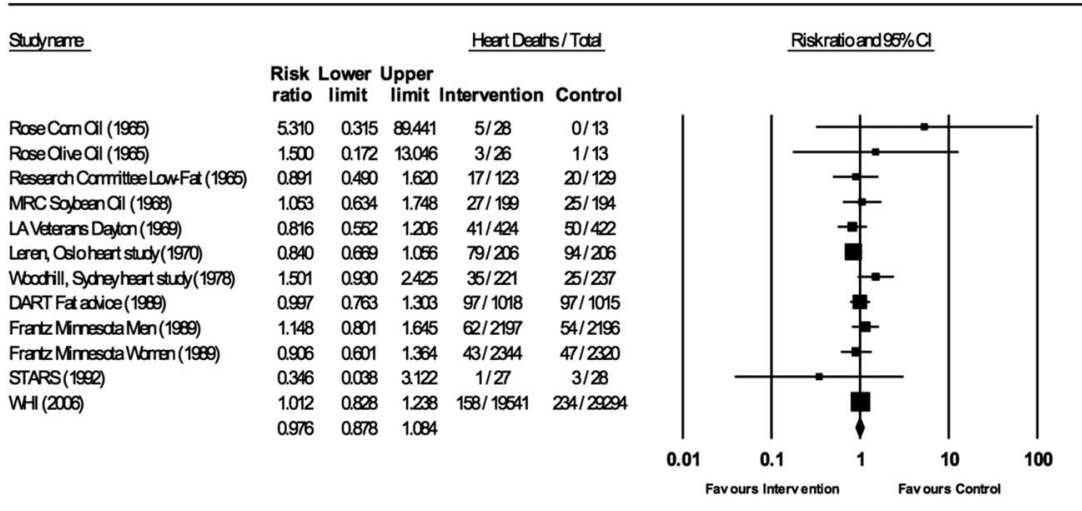

Meta Analysis random effects method

Table 1 Outcome data from included trials of diet and events for intervention (Int) and control (Ctrl) groups

\begin{tabular}{|c|c|c|c|c|c|c|c|}
\hline \multirow[b]{2}{*}{ Study } & \multirow{2}{*}{$\begin{array}{l}\text { Participants } \\
\text { Int/Ctrl }\end{array}$} & \multicolumn{3}{|c|}{ Intervention } & \\
\hline & & Type & Years & Diet & $\begin{array}{l}\text { All deaths } \\
\text { Int/Ctrl }\end{array}$ & $\begin{array}{l}\text { CHD } \\
\text { deaths } \\
\text { Int/Ctrl }\end{array}$ & $\begin{array}{l}\text { Change in mean } \\
\text { serum cholesterol } \\
\text { Int/Ctrl (\%) }\end{array}$ \\
\hline Rose Corn oil & 28/26* (M under & $\mathrm{S}$ & 2 & $64 \mathrm{~g}$ corn oil/day & $5 / 1^{*}$ & $5 / 1^{*}$ & $-7.6 /-1.2$ \\
\hline Rose Olive oil ${ }^{14}$ & $\begin{array}{l}70) \\
26 / 26^{*} \text { (M under } \\
70)\end{array}$ & & & $\begin{array}{l}58 \mathrm{~g} \text { olive oil/day }+ \\
\text { many banned foods }\end{array}$ & $3 / 1^{*}$ & $3 / 1^{*}$ & $-0.4 /-1.2$ \\
\hline Low-fat Diet ${ }^{19}$ & $\begin{array}{l}123 / 129(\mathrm{M} \\
\text { under } 65)\end{array}$ & $\mathrm{S}$ & 3 & $40 \mathrm{~g}$ fat/day & $20 / 24$ & $17 / 20$ & $-16.9 /-12.4$ \\
\hline $\begin{array}{l}\text { MRC } \\
\text { Soya-bean Oil }\end{array}$ & $\begin{array}{l}199 / 194(\mathrm{M} \\
\text { under } 60)\end{array}$ & $\mathrm{S}$ & 3.4 & $\begin{array}{l}85 \text { g soya-bean oil/ } \\
\text { day + many banned } \\
\text { foods }\end{array}$ & $28 / 31$ & $27 / 25$ & $-16.9 /-5.9$ \\
\hline $\begin{array}{l}\text { LA Veterans } \\
\text { Study }^{21}\end{array}$ & $\begin{array}{l}424 / 422(\mathrm{M} \text { age } \\
55+)\end{array}$ & $\mathrm{P} / \mathrm{S}$ & 8 & $\begin{array}{l}40 \% \text { calories from fat, } \\
2 / 3 \text { fat from veg oils }\end{array}$ & $174 / 177$ & $41 / 50$ & $-18.0 /-14.1$ \\
\hline $\begin{array}{l}\text { Oslo Diet-Heart } \\
\text { Study }^{20}\end{array}$ & $\begin{array}{l}206 / 206 \text { (M 30- } \\
64 \text { years) }\end{array}$ & $\mathrm{S}$ & 11 & $\begin{array}{l}40 \% \text { calories from fat, } \\
72 \% \text { fat from } \\
\text { soya-bean oil }\end{array}$ & $101 / 108$ & $79 / 94$ & $\begin{array}{l}-17.6 /-3.7 \text { (5-year } \\
\text { data) }\end{array}$ \\
\hline $\begin{array}{l}\text { Sydney Diet } \\
\text { Heart Study }{ }^{15}\end{array}$ & $\begin{array}{l}221 / 237 \text { ( } \mathrm{M} \mathrm{30-} \\
59 \text { years) }\end{array}$ & $\mathrm{S}$ & 5 & $\begin{array}{l}10 \% \text { sat } / 15 \% \text { poly vs } \\
14 \% \text { sat } / 9 \% \text { poly }\end{array}$ & $39 / 28$ & $35 / 25$ & $-11.0 /-7.1$ \\
\hline $\begin{array}{l}\text { DART Fat } \\
\text { advice }^{27}\end{array}$ & $\begin{array}{l}\text { 1018/1015 (M } \\
\text { under } 70)\end{array}$ & $\mathrm{S}$ & 2 & Total fat $30 \% \mathrm{P} / \mathrm{S}=1$ & $111 / 113$ & 97/97 & $-2.8 /+1.2$ \\
\hline Minnesota & $4393 \mathrm{M}$ & $\mathrm{P}$ & 1 & Ctrl: $39 \%$ calories fat & $158 / 153$ & $62 / 54$ & Cholesterol not \\
\hline Coronary & $4664 \mathrm{~W}$ (all ages) & & & (18\% sat; $5 \%$ poly; & $111 / 95$ & $43 / 47$ & reported separately for \\
\hline Survey $^{22}$ & $2197 / 2196$ & & & $16 \%$ mono) & & & men/women \\
\hline $\begin{array}{l}\text { Men } \\
\text { Women }\end{array}$ & $2344 / 2320$ & & & $\begin{array}{l}\text { Int: } 38 \% \text { calories fat } \\
\text { (9\% sat; } 15 \% \text { poly; } \\
14 \% \text { mono) }\end{array}$ & & & $-15.5 /-1.9$ \\
\hline STARS $^{28}$ & $\begin{array}{l}27 / 28 \text { (M under } \\
66 \text { ) }\end{array}$ & $S$ & 3.25 & $\begin{array}{l}27 \% \text { calories fat } \\
\text { (8-10\% sat; } 8 \% \text { poly) }\end{array}$ & $1 / 3$ & $1 / 3$ & $-14.0 /-1.8$ \\
\hline $\mathrm{WH} \mathrm{I}^{29}$ & $\begin{array}{l}19541 / 29294 \\
\text { (W 50-79 years) }\end{array}$ & $\mathrm{P} / \mathrm{S}$ & 8.1 & $\begin{array}{l}20 \% \text { calories fat; } 7 \% \\
\text { calories sat fat }\end{array}$ & $950 / 1454$ & $158 / 234$ & $\begin{array}{l}-4.4 /-3.4 \text { (3-year } \\
\text { data) }\end{array}$ \\
\hline Total & $26354 / 36067$ & & & & $1701 / 2187$ & $568 / 650$ & $\begin{array}{l}\text { Mean }-11.4 \% /-4.7 \% \\
\text { SD } 6.5 / 4.8\end{array}$ \\
\hline
\end{tabular}


implausible (egg consumption quantified, vegetable oils added and animal fats restricted). The Minnesota Coronary Survey was reported as double blinded and this was plausible given the dietary intervention. ${ }^{22}$ The open enrolment and departure in the LA Veterans and Minnesota institutions ${ }^{21}{ }^{22}$ produced attrition bias. The STARS $^{28}$ was judged unclear for attrition bias for the relatively high number of dropouts in small participant numbers. All studies were judged low risk for reporting bias, as there was no evidence of any data being withheld (figure 2).

The meta-analyses for all-cause mortality (figure 3) and CHD deaths (figure 4) were tested for sensitivity analysis of the exclusion of any one study. There were no circumstances in which the exclusion of any one study made the overall effect size significant.

There was little evidence for between-study heterogeneity. For all deaths, the Q-value was 7.915 (11 df), but this was not statistically significant; $\mathrm{p}=0.721$. $\mathrm{I}^{2}$ was 0.000 and $\mathrm{T}^{2}$ was 0.000 , indicating no difference in true effects. For CHD deaths, the Q-value was 9.173 (11 df), but this was also not statistically significant; $p=0.606$. $\mathrm{I}^{2}$ was 0.000 and $\mathrm{T}^{2}$ was 0.000 .

Visual inspection of the funnel plots revealed that one study was touching the outside of the SE funnel for the meta-analysis of all deaths and CHD deaths. The two, small, oil interventions ${ }^{14}$ produced asymmetry on the lower right-hand side of the funnel, which was countered by the small STARS representation on the lower left-hand side. ${ }^{28}$ The Egger's regression test indicated no statistically significant asymmetry for all-cause mortality and CHD deaths. The Egger's regression intercept was 0.337 (95\% CI, two-tailed, -0.489 to 1.163) (one-tailed $\mathrm{p}=0.192$; two-tailed $\mathrm{p}=0.384$ ) for allcause mortality and 0.380 (95\% CI, two-tailed, -0.756 to 1.517 ) (one-tailed $\mathrm{p}=0.237$; two-tailed $\mathrm{p}=0.473$ ) for CHD deaths.

\section{Interventions and comparisons}

A total of 6 of the 10 RCTs did not examine either of the introduced dietary guidelines: a total fat consumption of $30 \%$; or a SFA consumption of $10 \%$, of energy intake. ${ }^{14} 18-2129$ Four trials examined the administration of vegetable oil, ${ }^{14} 182021$ to effect reduced intake of animal fat. The Research Committee Low-fat Diet ${ }^{19}$ and the $\mathrm{WHI}^{29}$ studied an approximate $20 \%$ fat diet. Woodhill et $a l^{15}$ and Frantz et $a l^{22}$ reviewed the consequence of a $10 \%$ SFA diet, without the total fat dietary guideline restriction. Woodhill et al reported higher incidence of all-cause mortality and CHD deaths in the intervention group. Frantz et al recorded no difference in all-cause mortality or CHD deaths. The DART ${ }^{27}$ tested a $30 \%$ total fat diet although this was not a controlled variable, as the intervention also tried to achieve a 1:1 polyunsaturated to SFA ratio. The STARS ${ }^{28}$ was the first to examine targets approximating to those set by dietary guidelines with a total fat consumption of $27 \%$ and an $8-10 \%$ SFS intake.

\section{Outcomes: all-cause mortality}

Across 10 studies, containing 12 dietary interventions, involving 26354 participants in the intervention groups and 36067 participants in the control groups, there were 1701 deaths in the intervention and 2187 deaths in the control groups. All-cause mortality was $6.45 \%$ in the intervention groups and $6.06 \%$ in the control groups.

For all-cause mortality, the WHI study ${ }^{29}$ carried the greatest weight, $54.35 \%$ (figure 3; random-effects methodology). Three studies, comprising four interventions, carried a combined weight of $35 \% .^{20-22}$ The Rose $e a^{14}$ corn and olive oil interventions had negligible impact on the overall effect, with weights of $0.04 \%$ and $0.07 \%$, respectively, as did the STARS with a weight of $0.07 \% .^{28}$ The RR for all 12 interventions was 0.991 (95\% CI 0.935 to 1.051). The overall effect measurement lies on the line of no effect. There was no statistically significant difference between dietary interventions and all-cause mortality.

\section{CHD mortality}

The 12 interventions recorded 568 deaths from CHD among 26354 participants in the intervention groups and 650 deaths from CHD among 36067 participants in the control groups. The death rates for CHD mortality were $2.16 \%$ and $1.80 \%$ in the intervention and control groups, respectively. The forest plot for the dietary interventions and deaths from CHD produced the meta-analysis shown in figure 4 (random-effects methodology).

For CHD mortality, the WHI study ${ }^{29}$ carried the greatest weight, $27.59 \%$ (figure 4; random-effects methodology). The Oslo study ${ }^{20}$ was comparable with a weight of $21.36 \%$ and the DART ${ }^{27}$ contributed $15.56 \%$ to the weighting. The Rose $e t a l^{14}$ corn and olive oil interventions had negligible impact on the overall effect, with weights of $0.14 \%$ and $0.24 \%$, respectively, as did the STARS with a weight of $0.23 \% .^{28}$ The RR for all 12 interventions was 0.976 (95\% CI 0.878 to 1.084$)$. The overall effect measurement lies on the line of no effect. There was no statistically significant difference between the dietary interventions and heart deaths.

\section{Serum cholesterol levels}

Mean serum cholesterol levels decreased in all groups, control and intervention, except for the DART, ${ }^{27}$ where cholesterol levels were $1.2 \%$ higher in the control group after 2 years. This was unlikely to be clinically relevant. ${ }^{35}$ None of the reductions in mean serum cholesterol levels exceeded the critical difference of $19 \%$, calculated by Fraser and Fogarty ${ }^{35}$ as the requirement for significance $(\mathrm{p}<0.05)$.

Three studies alone ${ }^{15} 2728$ reported SDs and significance for the start and end-of-study mean serum cholesterol levels. The one figure reported as statistically significant was the $14 \%$ reduction in mean serum cholesterol levels in the intervention group in the STARS $(\mathrm{p}<0.001){ }^{28}$ The 8 -year WHI study $^{29}$ reported the 
reductions in mean serum cholesterol levels in the intervention and control groups as $10.2 \pm 32.0 \mathrm{mg} / \mathrm{dL}$ and 6.9 $\pm 31.9 \mathrm{mg} / \mathrm{Dl}$, respectively, and reported the difference between the reductions, $3.26 \mathrm{mg} / \mathrm{dL}$, as significant at $\mathrm{p}<0.05$ from a 2 -sample test.

The standardised mean difference in serum cholesterol levels, for the 10 trials (12 interventions) combined, was $-11.4 \% \pm 6.5 \%$ for the intervention groups and $-4.7 \% \pm 4.8 \%$ for the control groups (table 1 ). The effect size was 1.18.

\section{DISCUSSION}

The main findings of our systematic review and meta-analysis are that currently available RCT evidence does not support the current dietary fat guidelines. RCT evidence indicates that dietary modification may reduce serum cholesterol to a marginally greater extent in intervention groups, compared with controls. However, this reduction in serum cholesterol does not appear to translate into an improved survival from all causes or CHD.

\section{Design limitations}

As noted in the introduction, the fundamental design limitation of dietary fat interventions available to inform public health advice is that only one study ${ }^{22}$ has been undertaken involving men and women without previous heart disease. All other RCTs have been single-sex and/or secondary prevention studies.

The method of extracting dietary information was a limitation of all studies. Dietary recall is generally unreliable and 24-hour recall may not be representative of usual diet. ${ }^{36}{ }^{37}$ Dietary surveys, where food is weighed at the time of being recorded, are also unreliable. ${ }^{38} 39$

Woodhill et al noted that it is 'insuperable' to isolate dietary factors in a secondary prevention study. This is a flaw of all secondary prevention studies, not a unique flaw of this study. The study noted that changes in smoking habit, dietary pattern, body weight, lifestyle and physical activity before and after entry to the trial may have had a significant effect on prognosis (page 326). ${ }^{15}$

There are some additional design limitations among the available RCTs, which may confound interpretation. A number of studies ${ }^{14} 181928$ impaired assessment of the primary dietary intervention by adding other dietary restrictions, such as the avoidance of processed foods. This would impact industrially produced trans fat intake, which is associated with CHD. ${ }^{8}{ }^{40}$ The low-fat diet ${ }^{19}$ resulted in the calorie intake in the intervention group ranging between 330 and 780 calories fewer than that of the control group. At the largest differential, observed after 4 years of the study, the diet group was consuming $70 \%$ of the calorie intake of the control group. This study reported mean weight loss as $7.5 \%$ in the intervention group and $4.8 \%$ in the control group. This may have favoured the intervention outcomes. The STARS ${ }^{28}$ may also have favoured the intervention group by restricting participants to $1200 \mathrm{kcal}$ daily until a body mass index (BMI) of 25 was achieved. Further, dietetic counselling and suitable foods were given to participants in the intervention group who did not achieve or maintain serum cholesterol reductions of $15 \%$, making serum cholesterol levels a target, not an outcome.

The LA Veterans Study ${ }^{21}$ recorded the lowest RR for CHD deaths for the intervention group: 0.816 (95\% CI 0.552 to 1.206 ) (figure 3). However, there were important differences in the groups at study entry, favouring the intervention outcomes: $2.8 \%$ of the intervention group were octogenarians, compared with $5 \%$ in the control group; $11 \%$ of the experiment group were heavy smokers (more than one pack a day) compared with $17 \%$ of the control group.

Additional limitations were the short duration (1 year) of the second largest study, the Minnesota Coronary Survey with 9057 participants. ${ }^{22}$ Two of the studies were small, ${ }^{14}{ }^{28}$ although meta-analysis weights this accordingly. Leren ${ }^{20}$ benefited from trial length, but the study discussion noted that the test groups were too small to be significant for fatal incidences. The summary also reported that CHD mortality was correlated with age, blood pressure, body weight, smoking habits and a combination of these factors, meaning that the association with diet alone could not be isolated.

The WHI study ${ }^{29}$ was of substantial size and duration, but with a number of confounding variables. It was limited in its focus on postmenopausal women, aged between 50 and 79, and who were not already consuming dietary fat below $32 \%$ of total calorie intake. Participants were additionally invited to receive hormone therapy and participation in a calcium/ vitamin D supplement trial was offered after 1 year. This study alone included cholesterol-lowering medication, which was taken by $12 \%$ of participants in the intervention and control groups.

A limitation of the meta-analysis of the 10 studies combined was that all RCTs differed in duration; number of participants; nature of intervention; other factors held constant and subject age groups, undermining possible conclusions, although the statistical homogeneity helps to mitigate concerns.

\section{Study conclusions}

Only one of the 10 RCTs presented a case for dietary guidelines. The STARS $^{28}$ claimed that its findings supported the use of a lipid-lowering diet in men with CHD. The 5-year review of the Oslo Diet-Heart Study ${ }^{26}$ concluded that the cholesterol-lowering diet reduced the incidence of total CHD relapses. The conclusion after 11 years was more reserved: that sudden death in survivors of myocardial infarction was uninfluenced by diet. $^{20}$

Four studies were neutral in their findings. ${ }^{18} 222729$ The MRC study found no evidence from the London trial that the relapse rate in myocardial infarction is materially affected by the unsaturated fat content of the diet. $^{18}$ The DART ${ }^{27}$ made no claim for dietary fat 
reductions, but concluded that two to three portions of fatty fish each week may reduce mortality in men who have recovered from a myocardial infarction. The Minnesota Coronary Survey ${ }^{22}$ found no differences between the treatment and control groups for cardiovascular events, cardiovascular deaths or total mortality. The $\mathrm{WHI}^{29}$ reported that an $8.2 \%$ energy decrease in total fat intake had been achieved and a $2.9 \%$ energy decrease in SFA intake, but that this did not reduce risk of CHD.

The other four studies issued cautions about the safety and/or efficacy of their interventions. ${ }^{14} 151921$ Rose et $a l^{14}$ reported that corn oil was most unlikely to be beneficial, and was possibly harmful. The Research Committee ${ }^{19}$ concluded that a low-fat diet has no place in the treatment of myocardial infarction. Dayton et $a l^{21}$ noted the absence of any benefit for longevity and expressed concern about toxicity of the intervention. Woodhill et $a l^{15}$ reported that survival was significantly better in the control than the diet group.

This meta-analysis of 10 RCTs, in comparison with Harcombe et al's review of 6 RCTs, ${ }^{3}$ increased the number of people studied from 2467 to 62447 . It increased the number of women studied from 0 to 53499 , the majority. It increased the number of primary prevention subjects from $676^{21}$ to 56291 . However, $83 \%$ of the primary prevention subjects were postmenopausal women, so the concern about generalisability remains for guidelines introduced for whole populations.

\section{Review of dietary guidelines}

The US dietary guidelines advisory committee (DGAC) report was published in February 2015. ${ }^{41}$ The recommendation to limit dietary cholesterol intake to $300 \mathrm{mg}$ a day has prevailed in the USA since $1977 .{ }^{1}$ The DGAC stated that they will not bring forward this recommendation, because available evidence shows no appreciable relationship between consumption of dietary cholesterol and serum cholesterol. ${ }^{41}$ The UK did not introduce dietary cholesterol targets in the original guidelines ${ }^{2} 42$ and they have not been introduced since. ${ }^{43}$

The DGAC advice demonstrated further movement away from the original dietary guidelines by containing no total fat recommendation and a change in position on dietary fat and CVD. The advisory report documented the findings of the meta-analyses by Skeaff, ${ }^{4}$ Siri-Tarino, ${ }^{5}$ Hooper $^{6}$ and Chowdhury, ${ }^{8}$ and concluded that reducing total fat does not lower CVD risk. ${ }^{41}$ The SFA guideline was reiterated, however, with the recommendation to consume $<10 \%$ of total calories from SFA per day. ${ }^{41}$

The UK does not review dietary guidelines at regular intervals. The target for total fat remains $30 \%$ of daily total energy intake and $10 \%$ for SFA. ${ }^{43}$

Dietary fat guidelines were introduced with the intention of reducing CHD mortality. No meta-analysis has found any significant difference for dietary fat interventions and all-cause mortality or deaths from
CHD. $^{3-8} 1044$ All but one study ${ }^{22}$ is of single-sex and/or secondary prevention subjects. Even in men who have already suffered a myocardial infarction, evidence does not support dietary recommendations; yet they have been issued for millions of citizens for three to four decades.

The most recent meta-analysis, ${ }^{7}$ with the same singlesex, secondary prevention limitations, suggested that there may be a small reduction in cardiovascular risk on reduction of SFA intake. It was further suggested that replacing the energy from SFA with polyunsaturated fat appeared to be a useful strategy, while replacement with carbohydrate appeared less useful and replacement with monounsaturated fat unclear. Of the 11 interventions contributing to this conclusion, only one documented both SFA reduction and reported that this was mainly replaced with polyunsaturated fat. ${ }^{21}$

The future will undoubtedly consist of the tailoring of diets and lifestyle to individual genomic make-up. ${ }^{45}$ This will require the understanding of the genomic structure of circulating lipid profiles and replicable data on genes and diet interaction. Caution will be required in translating contemporary research on gene diet and lifestyle into public health advice.

It is important that we learn from the study limitations and lack of evidence on which current guidelines are based and not make the same mistake with future guidelines or suggestions. Harcombe $e t a l^{3}$ found that the dietary fat guidelines were not evidence based. This paper reiterates the finding and recommends that national dietary advice needs urgent review.

Twitter Follow Zoe Harcombe at @zoeharcombe

Contributors $\mathrm{ZH}$ conceived of the study and was the major contributor to data extraction, writing of the manuscript and the meta-analysis. BD was involved in data extraction, writing of the manuscript and the meta-analysis. Other authors were involved in critical evaluation of content.

Competing interests The authors confirm that they have no conflicts of interest regarding the funding or outcomes of the above study. The study was not funded (either in full or in part) by any private, charitable or government institutions. No financial payments were received for any aspect of the above work. There are no financial relationships with any third party entities relating to the above work, nor are there any patents (either submitted or planned) relating to the study. In addition to the above, $\mathrm{ZH}$ receives income from writing and from two small self-employment businesses: The Harcombe Diet Co. and Columbus Publishing.

Provenance and peer review Not commissioned; externally peer reviewed. Data sharing statement No additional data are available.

Open Access This is an Open Access article distributed in accordance with the Creative Commons Attribution Non Commercial (CC BY-NC 4.0) license, which permits others to distribute, remix, adapt, build upon this work noncommercially, and license their derivative works on different terms, provided the original work is properly cited and the use is non-commercial. See: http:// creativecommons.org/licenses/by-nc/4.0/

\section{REFERENCES}

1. Select Committee on Nutrition and Human Needs. Dietary goals for the United States. 1st edn. Washington: U.S. Govt. Print. Off, 1977.

2. National Advisory Committee on Nutritional Education (NACNE). A discussion paper on proposals for nutritional guidelines for health education in Britain. London: The Health Education Council, 1983. 
3. Harcombe Z, Baker JS, Cooper SM, et al. Evidence from randomised controlled trials did not support the introduction of dietary fat guidelines in 1977 and 1983: a systematic review and meta-analysis. Open Heart 2015;2:e000196.

4. Skeaff CM, Miller J. Dietary fat and coronary heart disease: summary of evidence from prospective cohort and randomised controlled trials. Ann Nutr Metab 2009;55:173-201.

5. Siri-Tarino PW, Sun Q, Hu FB, et al. Meta-analysis of prospective cohort studies evaluating the association of saturated fat with cardiovascular disease. Am J Clin Nutr 2010;91:535-46.

6. Hooper L, Summerbell CD, Thompson R, et al. Reduced or modified dietary fat for preventing cardiovascular disease. Cochrane Database Syst Rev 2011;(7):CD002137.

7. Hooper L, Martin N, Abdelhamid A, et al. Reduction in saturated fat intake for cardiovascular disease. Cochrane Database Syst Rev 2015;(6):CD011737.

8. Chowdhury R, Warnakula S, Kunutsor S, et al. Association of dietary, circulating, and supplement fatty acids with coronary risk: a systematic review and meta-analysis. Ann Intern Med 2014; 160:398-406.

9. Schwingshackl L, Hoffmann G. Dietary fatty acids in the secondary prevention of coronary heart disease: a systematic review, meta-analysis and meta-regression. BMJ Open 2014;4:e004487.

10. Mozaffarian D, Micha R, Wallace S. Effects on coronary heart disease of increasing polyunsaturated fat in place of saturated fat: a systematic review and meta-analysis of randomized controlled trials. PLoS Med 2010;7:e1000252.

11. Ravnskov $U$. The questionable role of saturated and polyunsaturated fatty acids in cardiovascular disease. J Clin Epidemiol 1998;51:443-60.

12. Stamler J. Diet-heart: a problematic revisit. Am J Clin Nutr 2010;91:497-9.

13. Ravnskov U, DiNicolantonio JJ, Harcombe Z, et al. The questionable benefits of exchanging saturated fat with polyunsaturated fat. Mayo Clin Proc 2014;89:451-3.

14. Rose GA, Thomson WB, Williams RT. Corn oil in treatment of ischaemic heart disease. BMJ 1965;1:1531-3.

15. Woodhill JM, Palmer AJ, Leelarthaepin B, et al. Low fat, low cholesterol diet in secondary prevention of coronary heart disease. Adv Exp Med Biol 1978;109:317-30.

16. Turpeinen $\mathrm{O}$, Karvonen MJ, Pekkarinen $\mathrm{M}$, et al. Dietary prevention of coronary heart disease: the Finnish mental hospital study. Int J Epidemiol 1979;8:99-118.

17. Miettinen M, Turpeinen O, Karvonen MJ, et al. Dietary prevention of coronary heart disease in women: the Finnish mental hospital study. Int J Epidemiol 1983;12:17-25.

18. Medical Research Council. Controlled trial of soya-bean oil in myocardial infarction: report of a research committee to the Medical Research Council. Lancet 1968;292:693-700.

19. Research Committee. Low-fat diet in myocardial infarction: a controlled trial. Lancet 1965;2:501-4.

20. Leren P. The Oslo Diet-Heart Study. Eleven-year report. Circulation 1970;42:935-42.

21. Dayton S, Pearce ML, Hashomoto S, et al. A controlled clinical trial of a diet high in unsaturated fat in preventing complications of atherosclerosis. Circulation 1969;40:II-1-II-63.

22. Frantz ID, Dawson EA, Ashman PL, et al. Test of effect of lipid lowering by diet on cardiovascular risk. The Minnesota Coronary Survey. Arteriosclerosis 1989;9:129-35.

23. Moher $\mathrm{D}$, Liberati $\mathrm{A}$, Tetzlaff $\mathrm{J}$, et al. Preferred reporting items for systematic reviews and meta-analyses: the PRISMA statement. J Clin Epidemiol 2009;62:1006-12.

24. National Institute of Clinical Excellence (NICE). Journals and databases. Secondary Journals and databases. 2014. http://www. library.nhs.uk/help/resource
25. Wood DN, Smith AW. SIGLE: A Model for International Cooperation. Interlending \& Document Supply 1993;21:18-22.

26. Leren $P$. The effect of plasma-cholesterol-lowering diet in male survivors of myocardial infarction. A controlled clinical trial. Bull $N$ Y Acad Med 1968;44:1012-20.

27. Burr ML, Fehily AM, Gilbert JF, et al. Effects of changes in fat, fish and fibre intakes on death and myocardial reinfarction: Diet and Reinfarction Trial (DART). Lancet 1989;2:757-61.

28. Watts GF, Lewis B, Brunt JN, et al. Effects on coronary artery disease of lipid-lowering diet, or diet plus cholestyramine, in the St Thomas' Atherosclerosis Regression Study (STARS). Lancet 1992;339:563-9.

29. Howard BV, Van Horn L, Hsia J, et al. Low-fat dietary pattern and risk of cardiovascular disease: the women's health initiative randomized controlled dietary modification trial. JAMA 2006;295:655-66

30. Estruch R, Ros E, Salas-Salvadó J, et al. Primary prevention of cardiovascular disease with a mediterranean diet. $N$ Engl J Med 2013;368:1279-90.

31. Higgins JPT, Altman DG, Gøtzsche PC, et al. The Cochrane Collaboration's tool for assessing risk of bias in randomised trials. BMJ 2011;343:d5928.

32. Egger M, Smith G, Schneider M, et al. Bias in meta-analysis detected by a simple, graphical test. BMJ 1997;315:629-34

33. Sterne JAC, Sutton AJ, loannidis JPA, et al. Recommendations for examining and interpreting funnel plot asymmetry in meta-analyses of randomised controlled trials. BMJ 2011;343:d4002.

34. Borenstein M, Hedges L, Higgins J, et al. Comprehensive Meta Analysis Version 2. 2 ed. Biostat, Englewood, 2005.

35. Fraser CG, Fogarty $Y$. Interpreting laboratory results. $B M J$ 1989;298:1659-60.

36. Willett WC. Nutritional epidemiology issues in chronic disease at the turn of the century. Epidemiol Rev 2000;22:82-6.

37. Beaton $\mathrm{GH}$, Milner J, McGuire $\mathrm{V}$, et al. Source of variance in 24-hour dietary recall data: implications for nutrition study design and interpretation. Carbohydrate sources, vitamins, and minerals. Am J Clin Nutr 1983;37:986-95.

38. Cook A, Pryer J, Shetty P. The problem of accuracy in dietary surveys. Analysis of the over 65 UK National Diet and Nutrition Survey. J Epidemiol Community Health 2000;54:611-16.

39. Archer E, Pavela G, Lavie CJ. The inadmissibility of what we eat in America and NHANES dietary data in nutrition and obesity research and the Scientific Formulation of National dietary guidelines. Mayo Clin Proc 2015;90:911-26.

40. de Souza RJ, Mente A, Maroleanu A, et al. Intake of saturated and trans unsaturated fatty acids and risk of all cause mortality, cardiovascular disease, and type 2 diabetes: systematic review and meta-analysis of observational studies. BMJ 2015;351:h3978.

41. Dietary Guidelines Advisory Committee. Scientific Report of the 2015 Dietary Guidelines Advisory Committee. In: Department of Health and Human Services (HHS), ed. 2015:571.

42. Committee on Medical Aspects of Food Policy (COMA). Diet and cardiovascular disease: report of the panel on diet in relation to cardiovascular disease, 1984.

43. Department of Health. Dietary Reference Values for Food Energy and Nutrients for the United Kingdom. In: Department of Health, ed. Report of the Panel on Dietary Reference Values of the Committee on Medical Aspects of Food Policy. The Stationery Office, 1991:212.

44. Hooper L, Summerbell CD, Higgins JPT, et al. Dietary fat intake and prevention of cardiovascular disease: systematic review. BMJ 2001;322:757-63

45. Stegemann $\mathrm{C}$, Pechlaner R, Willeit $\mathrm{P}$, et al. Lipidomics profiling and risk of cardiovascular disease in the prospective population-based Bruneck study. Circulation 2014;129:1821-31 